\title{
el desmoronamiento de los granitos y su conservakión
}

\author{
D. de Molnár D’Arkos, ing. dipl. de minas
}

La palabra granito deriva del latín: granum $=$ granos.

Como su nombre indica es una masa formada por granos, en la cual los componentes son el feldespato potásico, el cuarzo, un poco de plagioclasa y mica. Tenemos la costumbre de llamar y clasificar a los granitos según la coloración de sus cristales. Así se distingue el granito de biotita-muscovita, que llamamos también granito de dos micas; el granito de biotita; el de muscovita; el de anfíbol; el de anfíbol--biotita; el de augita, etc.

La estructura de los granitos es, en general, cristalina; el menos idiomorfo es el cuarzo, que ha cristalizado en último lugar.

En ciertos granitos los cristales de color oscuro se agrupan en uno o en otro sitio por grupos o en nidos. Son separaciones básicas y contienen minerales oscuros (magnetita, augita, anfíbol y biotita) que cristalizan al principio del enfriamiento del magma y pueden influenciar su valor decorativo. Se considera esta "slir" como última intrusion magmática en los granitos aún no completamente consolidados.

Como los granitos son piedras de montón, su dureza es, en todos los sentidos, generalmente la misma. La dureza de los granitos compuestos de granos grandes es frecuentemente menor que la de los granitos de grano fino.

Los granitos de grano fino, sobre todo cuando contienen micas en cantidad relativamente pequeña, logran una resistencia elevada. Si las micas se agrupan en montones o en bandas, influyen desfavorablemente en su resistencia. La presencia de anfíbol y de augita aumenta la resistencia cuando son oscuros; cuando sus colores son verdosos, denota un principio de descomposición; es decir, está empezando la formación de clorita.

Los feldespatos no deben ser ni turbios en su interior, ni reblandecidos, ni de un tamaño que pase del centímetro, porque en otro caso, como consecuencia de la desigual dilatación, la cual está en relación con la dirección o el sentido de los cristales mayores, pueden estallar.

Si el granito contiene mucho cuarzo, la desaparición de feldespato puede no ser muy peligrosa, pues los cristales de cuarzo que se tocan forman una red o reja.

Los granitos resisten bien los fenómenos atmosféricos cuando están compuestos de granos pequeños; y cuando todavía conservan la humedad natural de cantera se pueden tallar fácilmente.

Su color es estable, y puede ser gris, rosa, rojo, blanco, verdoso. Cuando contiene piritas, a causa de la influencia atmosférica se vuelve pálido; este cambio de color es provocado por 
la transformación de pirita en limonita, y la formación de ácido sulfúrico actúa como disolvente sobre la piedra. La pulimentación ayuda a aumentar la duración de la piedra. Las masas graníticas se separan en montones grandes e irregulares, lo cual permite la extracción de grandes bloques.

En algunas regiones tectónicamente muy afectadas, como es, por ejemplo, el Macizo de Liguria, de $16 \mathrm{~km}$ de largo y $8 \mathrm{~km}$ de ancho, situado entre los Alpes y los Apeninos, es imposible obtener grandes bloques porque las rocas están rotas.

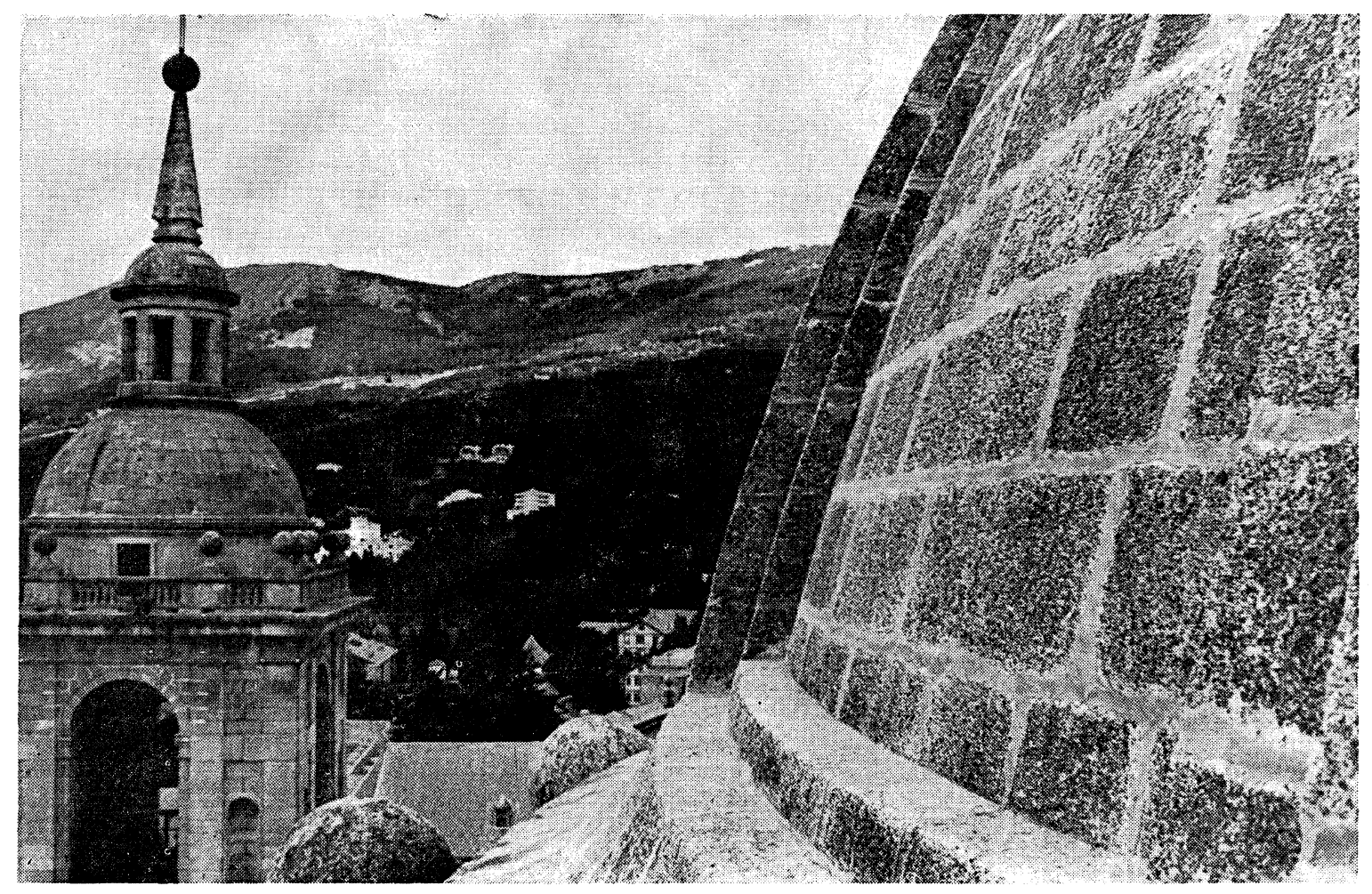

Los granitos se descomponen lentamente debido a la influencia atmosférica. Los bordes se redondean hasta que el bloque se convierte en una bola, muy caracteristico de las regiones graníticas, donde se encuentran frecuentemente enormes bloques esféricos.

En el curso del desmoronamiento, la biotita se altera y se torna pálida y el granito de grandes granos se desune en cuarzo granulado. El feldespato se transforma en caolín, el anfíbol en clorita y, en cualquier caso, la serpentina en epidoto. La limonita que se crea en detrimento de la biotita, colorea los granos de cuarzo en amarillo y marrón. El cuarzo químicamente no cambia y permanece sin transformar como residuo del desmoronamiento.

En el granito granulado se encuentran frecuentemente restos de feldespato, biotita pálida y algún mineral que se forme en el curso de su descomposición. En el granito descompuesto, la cantidad de $\mathrm{SiO}_{2}$ permanece casi como en estado original. La cantidad de calcio se reduce considerablemente, y la cantidad de sodio se reduce todavía más. En la descomposición más avanzada se forman también granos coloidales, y éstos absorben las sales de potasio. 
El desmoronamiento de los granitos en la naturaleza se facilita también por las fisuras, que es precisamente donde las aguas encuentran fácil penetración y el aire puede entrar profundamente.

El comportamiento de granitos sanos contra el hielo es satisfactorio. El hielo no ocasiona destrucción; solamente ocurre esto cuando los feldespatos están ya en descomposición, porque en este caso toda la estructura está ya adulterada.

Los granitos resisten menos el fuego, y son muy sensibles a los cambios bruscos de temperatura. Un granito calentado que encuentra agua de lluvia, crepita y desprende láminas de su superficie.

Es lógico que los granos oscuros absorban más calor que los claros. La diferencia de grado de dilatación de los granos explica también la descomposición.

Podemos distinguir dos tipos de desmoronamiento: el físico y el químico.

En el desmoronamiento de los granitos es frecuente encontrar a los dos juntos.

El desmoronamiento físico destruye la piedra en granulado; sus factores son la variación de la temperatura, el hielo, el efecto capilar del agua, etc. La variación de la temperatura hace dilatar y retraer los componentes del granito. En el calentamiento del aire por el sol, la parte exterior de la piedra estará más caliente que la interior y ocasionará tensiones, que no se pueden igualar más que con una disminución en la cohesión entre los cristales.

Sabemos, por ejemplo, que en El Escorial, durante el gran calor, un granito que llegue a temperaturas de más de $70^{\circ} \mathrm{C}$, al recibir bruscamente el agua de una tormenta se enfría hasta llegar a $15^{\circ} \mathrm{C}$ o menos, es decir, experimenta una diferencia de temperatura de $55^{\circ} \mathrm{C}$.

La absorción de calor de las piedras depende de su calor específico. El calor específico de las piedras es del orden de $1 / 4$ a $1 / 5$ del que tiene el agua; en consecuencia, una piedra se calienta más rápidamente que el agua.

Con $50^{\circ}$ a $70^{\circ} \mathrm{C}$ de diferencia de temperatura en la piedra puede ocasionarse un $1-2 \%$ de variación en la dilatación y retracción. Esta variación es suficiente para que las pequeñas fisuras producidas en el invierno se cierren en el verano.

El clima influye asimismo en los granitos. En el clima de Egipto, los obeliscos y columnas permanecen intactos durante muchos miles de años; sin embargo, una columna transportada de Egipto, en 1880, a New York - sobre este clima húmedo-, ha presentado en poco tiempo unos signos fuertes de descomposición, y fue necesario ya, en 1885, proceder a su conservación mediante un revestimiento de parafina que contenía creosota, pero el resultado no fue satisfactorio.

Puedo constatar que el aumento de volumen provocado por el calor hace variar la altura de arcos construidos en piedra cortada. Esta diferencia de altura provocada por la temperatura se puede medir fácilmente.

Una torre expuesta al sol aumenta de volumen y se inclina hacia el lado contrario del sol. El techo de la torre, si tiene una altura de 30 a $40 \mathrm{~m}$, describe una rotación -en 24 horas-; una curva, más o menos cerrada, de un diámetro, que varía entre 0,40 a 0,60 metros.

Este movimiento perpetuo ocasiona también en la cúpula del Monasterio de El Escorial tensiones considerables, que han adulterado la cohesión entre los granos componentes. 
Nos encontramos, por ejemplo, en El Escorial, bloques de granito tallado que provienen de la misma cantera, y situados uno al lado del otro; un bloque está perfectamente intacto y el otro se halla en descomposición, aunque durante su construcción y en siglos posteriores permanecieron inalterables. Esta descomposición se produce muchas veces químicamente, como explicaremos más adelante. Pero hemos visto casos en que esta descomposición es física, sobre todo si la descomposición no ha afectado más que a la superficie, debido a la orientación diferente de los cristales en los dos bloques.

La dilatación térmica de los minerales componentes de las piedras depende de la dirección. La dilatación de los cristales de un sistema regular o de un mineral amorfo es independiente de la dirección. Por ejemplo, una esfera de un ópalo permanece esférica para todas las temperaturas y sólo crece su radio; sin embargo, un cuarzo tallado en esfera y calentado disminuye en la dirección de su eje, y aumenta en la dirección perpendicular a su eje, transformándose en un elipsoide giratorio. El eje del elipsoide giratorio es el eje principal del cuarzo. El coeficiente de dilatación térmica lineal del cuarzo es 0,00000781 en la dirección del eje $\mathbf{y}$ de 0,00001419 en todas las otras direcciones perpendiculares al eje.

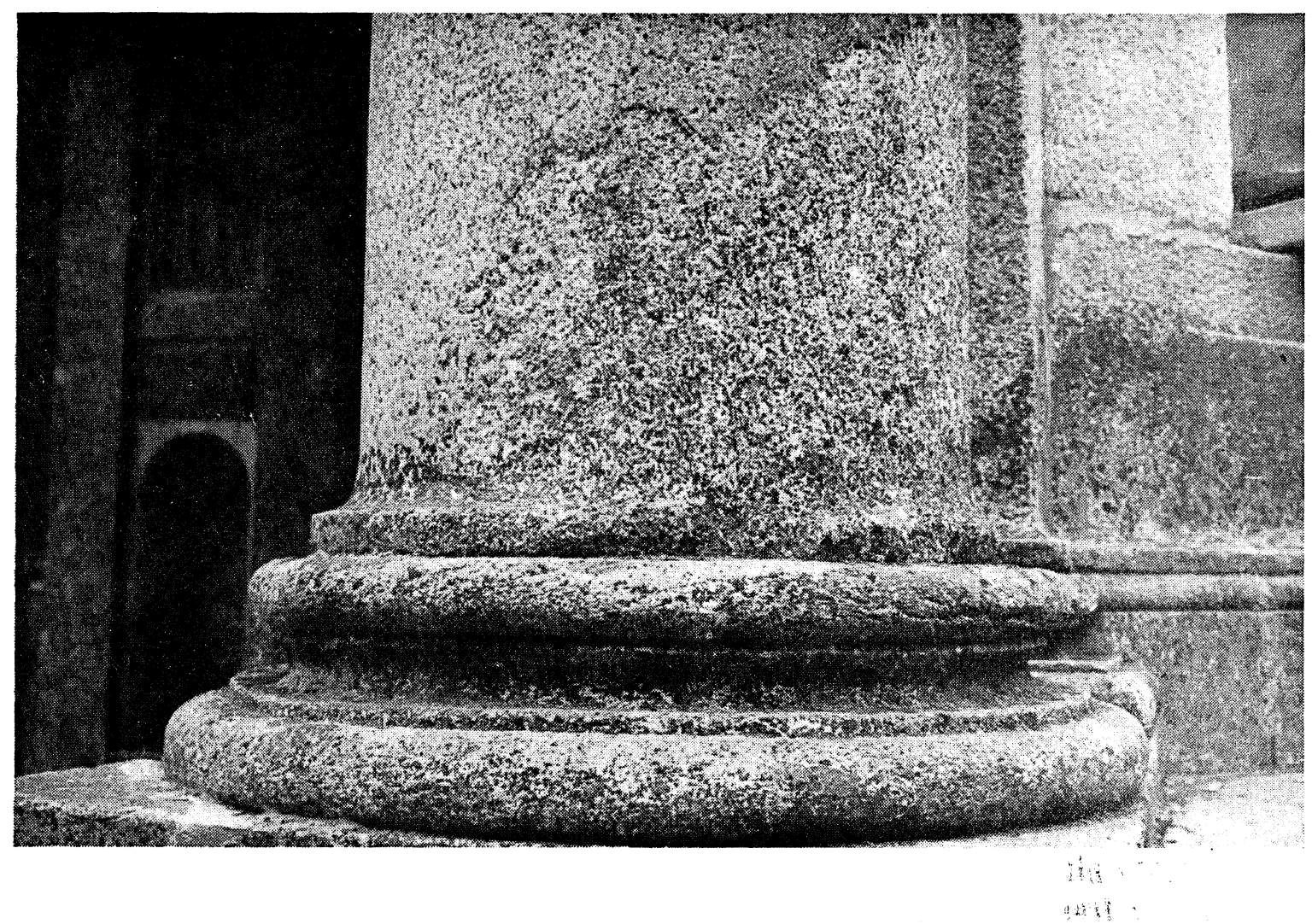

El coeficiente medio de dilatación térmica en volumen del cuarzo es 0,0000362 y el coeficiente de compresibilidad es 0,0000027 . Sobre esta base, el calentamiento de $20^{\circ}$ a $60^{\circ} \mathrm{C}$ corresponde a una presión de 535 megabar $=545,28 \mathrm{~kg} / \mathrm{cm}^{2}$.

La presión en las piedras de montón como el granito tiene, aproximadamente, el mismo orden de valor.

La repetición constante de la dilatación y a retracción produce el desmoronamiento de los minerales y se dislocan fácilmente, y en los otros ocasionan microfisuras. Como los mine- 
rales que componen la piedra no tienen la misma posición desde el punto de vista de dilatación térmica, ejercen una presión unos sobre otros. Sabemos por experiencia que las piedras compuestas de minerales oscuros y claros se fisuran más rápidamente que las que están formadas por minerales del mismo color.

Esta fisuración abre la puerta para el agua, que puede continuar la destrucción junto con el hielo.

Sería muy cómodo imputar el desmoronamiento de las piedras al hielo, pero el agua helada aumenta su volumen en $1 / 10$ y ejerce una presión del orden de $200 \mathrm{~kg} / \mathrm{cm}^{2}$. Esta presión debida al aumento del volumen tiene una fuerza capaz de hacer explotar tubos de acero cerrados, pero no ocasiona desgaste en un vaso abierto. Como el rocío que penetra en las fisuras de la piedra por capilaridad debe rellenar más de 0,9 las cabidades, engendra una presión; pero esta presión se crea solamente si os orificios de los poros están obstruidos y el hielo no puede salir al exterior.

El desmoronamiento de los granitos por el hielo es raro.

Se puede ver frecuentemente en tiempo frío a los granitos de El Escorial cubiertos de escarcha, lo cual es un signo inequivoco de que el agua helada sale a la superficie.

El comportamiento de la piedra contra el hielo se puede juzgar examinando el grado de saturación de sus cavidades. Se considera una piedra con buena resistencia contra el hielo, cuando su coeficiente en saturación es menor de $0,8(\mathrm{~S}<0,8)$. Este coeficiente de saturación se calcula por la fórmula:

$$
S=\frac{g_{1}}{g_{2}}
$$

en la que $g_{1}$ es la cantidad de agua que la piedra puede absorber por capilaridad en una simple inmersión, y $g_{2}$ es el peso del agua necesario para rellenar las cavidades íntegramente, comprimiéndose sobre el vacío, con una presión de 50 a 150 atmósferas.

En los granitos de El Escorial el desmoronamiento químico es considerablemente más importante que el físico. Los factores principales de desmoronamiento químico son: el agua y el $\mathrm{CO}_{2}$. También existe en el aire una pequeña cantidad de ácido nítrico y de amoníaco, que se forman durante las tormentas a causa de las descargas eléctricas. Cerca de $1 / 3$ del ácido carbónico disuelto en el agua está presente en forma de $\mathrm{H}_{2} \mathrm{CO}_{3}$, que es un ácido relativamente fuerte. El efecto disolvente del ácido nítrico no puede influir salvo si está en exceso, pero el amoniaco puede fijar una cantidad igual de ácido nítrico.

Es muy importante la cantidad de productos químicos que provienen de las plantas que penetran en las rocas, $\mathrm{y}$ son, fundamentalmente, los más destructivos.

Los primeros seres vivientes que se implantan en las rocas son las bacterias, las cuales producen el ácido nítrico. Estas toman su ácido carbónico en las sales minerales contenidas en las piedras, y transforman el amoníaco, que viene con el agua de lluvia, en ácido nítrico por oxidación. Estas bacterias penetran frecuentemente en las piedras hasta $1 \mathrm{~m}$ de profundidad - por las microfisuras y por las capas-, y son capaces de atacar también a los silicatos.

Sobre la piedra ya atacada por las bacterias viene a implantarse un liquen (el más esparcido Rhizocarpon Geograficum de un color verde vivo - verde amarillo). Ellos nacen de la simbiosis de las algas y de algunos hongos. Sus raíces, más finas que la seda, penetran profundamente y ningún silicato puede resistir contra el ácido carbónico y otros ácidos fuertes que producen. Lo más frecuente es que em jiecen su destrucción penetrando sus raíces en 
los minerales fácilmente hendibles en el sentido natural de sus capas, como, por ejemplo, la mica.

Las algas que cubren frecuentemente a las piedras están protegidas contra la desecación por una capa gelatinosa y producen también ácido carbónico que actúa como disolvente sobre la piedra. Examinando los granitos de apariencia sana, se encuentran algas de la familia de las diatomeas en el mismo interior de sus capas. No es nada extraordinario ver piedras, unas al lado de las otras, unas en estado avanzado de desmoronamiento, y otras no. Unas pueden estar ya contaminadas antes de su extracción de la cantera, sin que sea visible, y aun procediendo probablemente de menos profundidad que las otras.

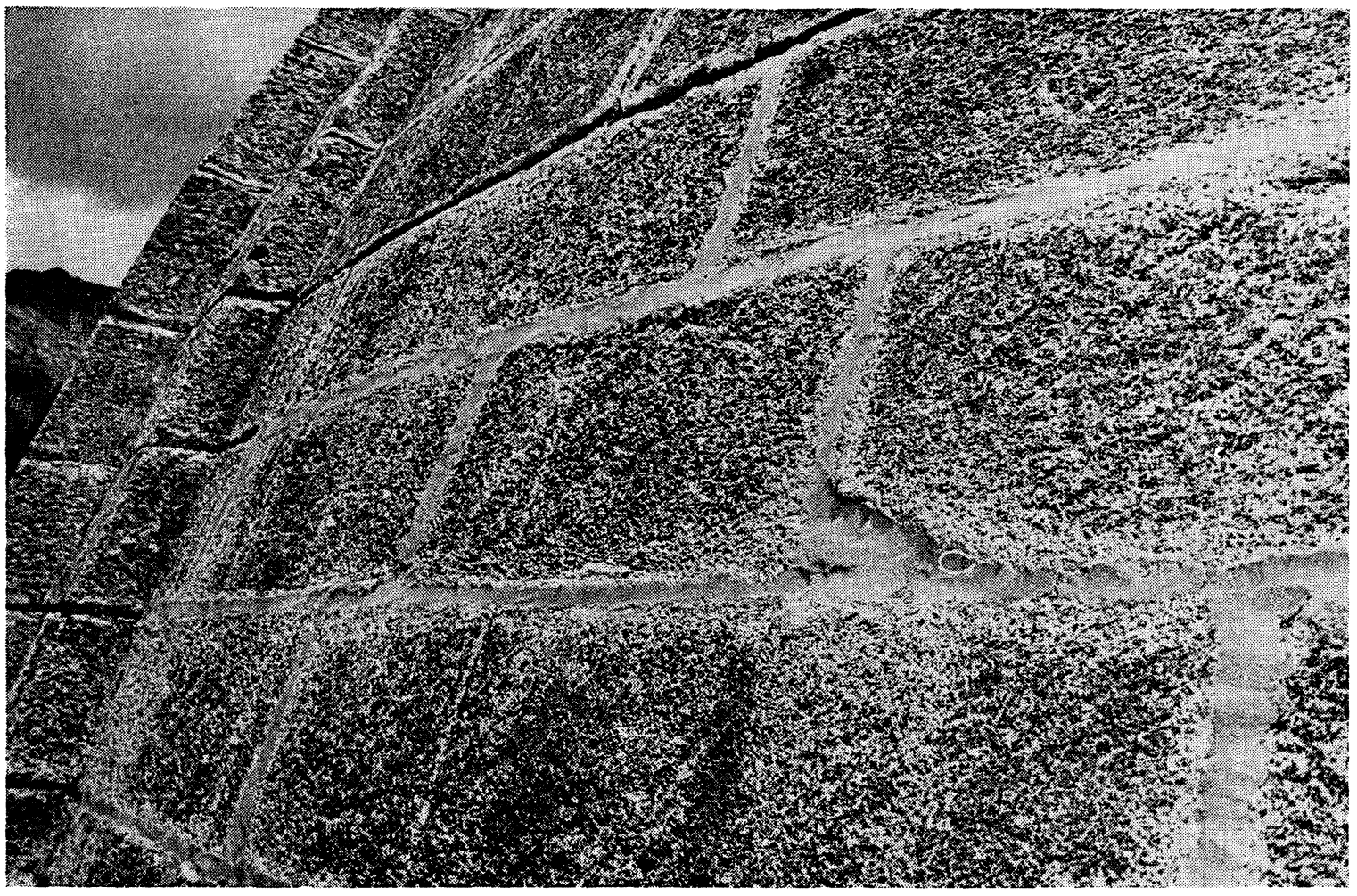

\section{la protección y conserwación de los granitos}

El problema no es simple. Vista la complejidad del origen de las enfermedades es necesario estudiar todo problema individualmente. Antes de hacer cualquier tratamiento es indispensable destruir los organismos parásitos. Cuando esta destrucción está resuelta por los agrónomos, viene entonces el tratamiento propiamente dicho. Hemos visto que, debido a los cambios de temperatura, los poros de la piedra se abren y cierran, la presión por dilatación y retracción es enorme, la cohesión disminuye hasta 0 y el desmoronamiento continúa.

La impermeabilización por un silicato u otro producto que endurece en los poros sin ser capaz de absorber las tensiones ocasionará desprendimiento, y la conservación será de muy corta duración. Entre los productos de impermeabilización, los bituminosos no se pueden, naturalmente, tomar en consideración. 
Hemos de hacer ensayos con productos similares que se utilizan con éxito en la conservación o impregnación en la profundidad de los hormigones, porque las condiciones que se exigen en la impermeabilización del hormigón son las mismas que las que necesitan las piedras.

Estas condiciones son, esencialmente, las siguientes:

1) Resistencia al envejecimiento (ni oxidación ni cambio de color).

2) Elasticidad permanente.

3) Adherencia perfecta.

4) Penetración (baja viscosidad).

5) Resistencia contra los fenómenos atmosféricos, químicos y biológicos.

Con muchos años de experiencia, pensamos haber encontrado estas cualidades reunidas en algunas resinas sintéticas. Hemos hecho - y repetido - muchas pruebas con las resinas Sinmast con la base de Suton 200 y 300 , y el mejor resultado se ha obtenido con la resina de tipo $\mathrm{S} / 111$.

El mayor problema consistía en introducir la resina en los poros. Era necesario reducir la viscosidad de la resina con un disolvente reactivo sin disminuir la potencia adhesiva del cuerpo sólido; también era necesario encontrar el equilibrio en la solución para que la cantidad de resina fuera la precisa para tapar herméticamente los poros y permanecer elástica, sin dar

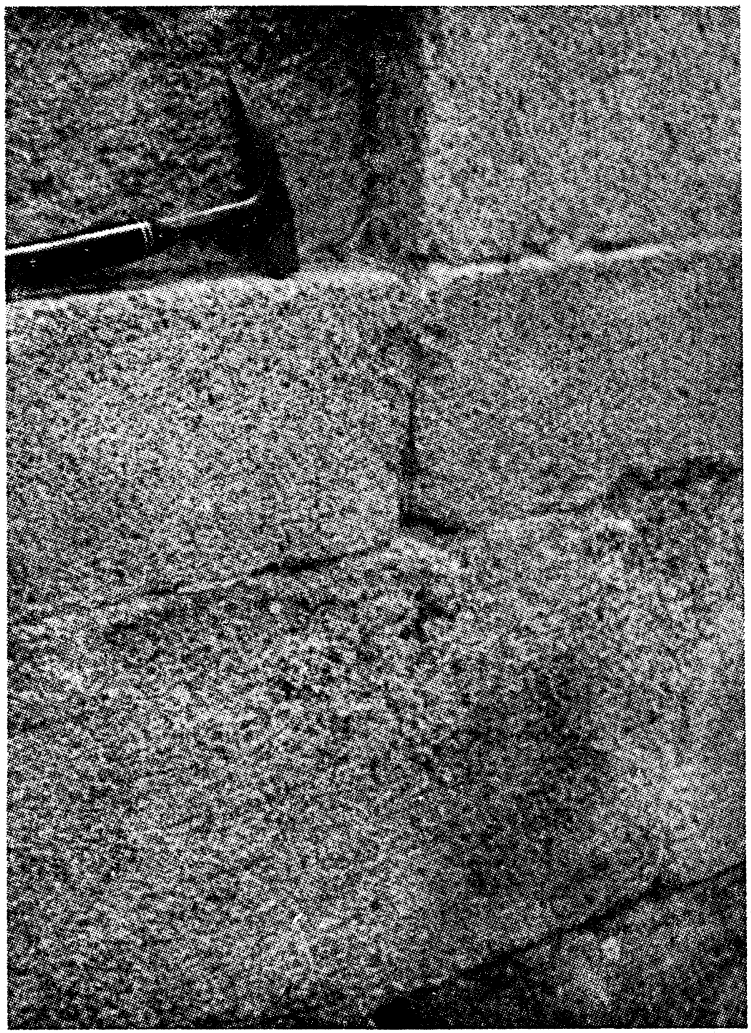
brillo a la piedra, pero que posea, al mismo tiempo, una resistencia suficiente para solidificar la piedra ya desmoronándose.

Todavía una palabra más sobre la limpieza de manchas de corrosión sobre los granitos. Si ellas provienen de la oxidación exterior (verja de hierro, etc.) es relativamente fácil quitarlas, pero cuando las manchas tienen su origen en la descomposición de los minerales contenidos en la piedra es necesario extremar las precauciones.

Las manchas de oxidación del granito cuando son solamente superficiales pueden eliminarse lavándolas con una solución reductora en medio ácido. Buenos resultados se han podido obtener con una solución conteniendo, por litro de agua, $50 \mathrm{~g}$ de cloruro estannoso $\left(\mathrm{Sn}_{\mathrm{Cl}}\right)$ y $5 \mathrm{~g}$ de ácido tartárico. Lavar después abundante y largo tiempo bajo una corriente de agua floja, pero continua, para quitar el hierro solidificado; el agua de lavado no debe conservar ninguna reacción ácida, lo que se comprueba con papel de tornasol aplicado sobre la piedra.

Cuando las manchas son más importantes (procedentes del troceado al hilo helicoidal), se necesita un tratamiento más enérgico; pero no hay que tratar de esta manera granito de mala calidad, demasiado poroso, ya que la solución continuará su acción corrosiva en profundidad y oxidará el hierro contenido en la mica, atacando de esta manera las piritas eventuales e invisibles en la superficie y las manchas reaparecerán. 